\title{
Transpetrosal approach to petro-clival meningioma
}

\author{
Turki Elarjani, MD, ${ }^{1}$ Rakshith Shetty, MD, ${ }^{1}$ Harminder Singh, MD, ${ }^{2}$ Harley B. da Silva MD, ${ }^{1}$ \\ and Laligam N. Sekhar, MD'
}

${ }^{1}$ Department of Neurological Surgery, University of Washington, Seattle, Washington; and 2Department of Neurological Surgery, Stanford University, Stanford, California

\begin{abstract}
A 38-year-old woman had a 3-week gradual onset of right-sided weakness in the upper and lower extremities. MRI showed a large left petro-clival meningioma encasing the basilar and left superior cerebellar artery and compressing the brainstem. A posterior transpetrosal approach, with a left temporal and retrosigmoid craniotomy and mastoidectomy, was performed. The tumor was removed in a gross-total resection with questionable remnants adherent to the brainstem. Intraoperative partial iatrogenic injury to the left oculomotor nerve was repaired with fibrin glue. Postoperatively, the hemiparesis improved, and the patient was discharged to the rehabilitation center with left oculomotor and abducens palsies. A postoperative MRI scan showed complete resection of tumor with no remnants on the brainstem. A 6-month follow-up examination showed complete resolution of motor symptoms and complete recovery of cranial nerve (CN) palsies affecting CN III and CN VI.
\end{abstract}

The video can be found here: https://youtu.be/vOu6YFA8uoo.

KEYWORDS petro-clival meningioma; skull base surgery; transpetrosal approach

SUBMITTED May 26, 2017. ACCEPTED June 28, 2017.

INCLUDE WHEN CITING Published online October 1, 2017; DOI: http://thejns.org/doi/abs/10.3171/2017.10.FocusVid.17214.

CORRESPONDENCE Laligam N. Sekhar, Department of Neurological Surgery, University of Washington, Harborview Medical Center, 325 Ninth Ave., Box 359924 , Seattle WA 98104. email: Isekhar@uw.edu. 